\title{
The use of price-to-earnings-to-growth (PEG) ratios to predict share performance on the JSE
}

\author{
T. l'Ons and M. Ward* \\ Gordon Institute of Business Science, \\ University of Pretoria, Republic of South Africa \\ mchlwrd@gmail.com
}

Received February 2011

\begin{abstract}
The effectiveness of the Price Earnings Growth ratio as a valuation tool has been a topical debate amongst analysts ever since being popularised by Lynch (1989). This study examines the appropriateness of the fair value criteria of a PEG of 1,0 , as proposed by Lynch $\left(\mathrm{PEG}_{\mathrm{L}}\right)$, and compares this with the time-series based, share specific model, proposed by Trombley (2008) $\left(\mathrm{PEG}_{\mathrm{T}}\right)$. In addition, the study analyses several factors which influence the accuracy of analyst's forecasts (viz. the number of analysts' contributions, the dispersion of forecasts and the forecast horizon), with the objective of identifying an optimal trading rule based on the PEG ratio.

We find consistent outperformance of the $\mathrm{PEG}_{\mathrm{T}}$ model. We also note (unexpectedly) that analyst's forecasting accuracy may have a less significant impact on the usefulness of the PEG ratio than their optimism. Finally, we report an optimised PEG trading rule which delivered annual abnormal returns of $13,7 \%$ over the study period. The trading rule appeared to single out small-capitalisation firms, with above market growth prospects, which performed well in a buoyant market.
\end{abstract}

*To whom all correspondence should be addressed.

\section{Introduction}

Dreman and Barry (1995) and Brown (1996) state that the primary use of analysts' earnings forecasts is to make investment decisions, and that investors rely heavily on analysts' views of future company performance to structure their investment portfolios. Stock valuation models, used extensively by analysts to identify investment opportunities, are underpinned by four main approaches: discounted dividends, asset valuation, cash flow analysis and relative valuation (Clemente, 1990), and enable analysts to project the following (Bradshaw, 2006):

- Earning forecasts, reported as Earnings Per Share (EPS);

- $\quad$ Stock recommendations (Buy, Hold or Sell);

- Target prices (future stock prices), and

- $\quad$ Risk ratings.

One of the more common practices amongst investors is to use the Price Earnings (PE) ratio as a simple valuation tool to determine whether a company's stock is over- or undervalued (Dudney, Jirasakildech \& Zorn, 2008). Since PE ratios fail to incorporate future earnings growth prospects, an improved valuation metric is the PriceEarnings-to-Growth (PEG) ratio (Trombley, 2008; Easton, 2004), which is essentially a stock's PE ratio divided by its expected earnings growth (Lynch, 1989). Whilst many investors have adopted the PEG ratio, others highlight the shortfalls of its simplicity. A recent survey of valuation practices established that 22 of 43 investment professionals use the PEG ratio as one of their valuation techniques (Trombley, 2008).

Schatzberg and Vora (2009) note that relatively few studies have been conducted on the usefulness of the PEG ratio, and those that do, focus on further improvements to the PEG ratio by incorporating additional variables into the metric, including adjustments for risk and the cost of capital (Trombley, 2008; Schnabel, 2009).

\section{Literature review}

Broadly speaking, valuation techniques fall into two widely researched investment styles, namely: value and growth strategies (Estrada, 2004). There are a large number of academic papers covering the relative performance of the two styles, with the overriding evidence that value strategies outperform growth strategies (Fama \& French, 1992; Estrada, 2004). In this genre, the price-earnings (PE) ratio is one of the oldest and most extensively used metrics. The term 'PE' refers to the ratio of a company's current share price to it's 'per share earnings'. This is calculated by dividing the current stock price of a company by its (last reported) ${ }^{1}$ earnings per share (EPS) (Investopedia, 2010b.).

\footnotetext{
'Often referred to as a "trailing" $\mathrm{P} / \mathrm{E}$ ratio, as opposed to a "leading" $\mathrm{P} / \mathrm{E}$ ratio, for which the denominator is the analyst's forecast of earnings per share.
} 
$\mathrm{PE}$ ratios typically range between $15-25$, but are contingent upon the economic conditions at the time, the industry sector and, in particular, the growth prospects for future earnings (Investopedia, 2002). Since a stock price reflects the future earnings potential of a company at any moment in time, companies with potentially strong earnings growth will show higher prices and thus higher PEs (and vice-versa) (Investopedia, 2002).

The PEG ratio was conceived in the 1960's by James D. Slater (Investopedia, 2010c.) and popularised in a New York Times bestseller: "One Up on Wall Street” by Lynch (1989). The PEG ratio is essentially the trailing $P E$ ratio of a company divided by the expected 'earnings growth' (' $G$ ') of that company, and is a means of explicitly factoring in a company's future earnings potential through the use of the objectively derived trailing PE. Lynch (1989: 198) outlines the benchmark parameters for utilising the PEG ratio, suggesting that a firm is "fully" valued when its trailing PE ratio approximates its short term growth rate (i.e. PEG = 1.0) and that stocks valued at a PEG $<0,5$ are most likely undervalued, while stocks valued above a PEG > 2,0 are most likely overvalued.

Estrada (2004), Trombley (2008) and Schnabel (2009) suggest that the PEG ratio needs to be further adjusted through the incorporation of a risk factor (the stock's beta value). Furthermore, Trombley (2008) and Schnabel (2009) both challenge Lynch's (1989) benchmarks and show empirically that by incorporating the cost of capital into the calculation, the metric can be improved. Trombley (2008) concludes that higher PEG ratios can be used for relatively low growth companies which also have a low cost of capital and that a PEG $=1.0$ is suitable for benchmarking high growth and high risk firms. He also suggests that the PEG ratio should not be used to choose amongst different types of stocks and that the tool should rather be used to compare stocks from similar industries, thereby standardising expected growth and capital costs.

Earnings growth estimates can be derived in many different ways. Lynch (1989) and Estada (2004) show preference for time-series models that use historical data to extrapolate future earnings growth, while others (eg Easton, 2004) use analysts' consensus forecasts of earnings growth. No matter how the forecast EPS is derived, an implied growth rate $(\mathrm{G} \%)$ can be calculated as follows:

$\mathrm{G} \%=\frac{\mathrm{EPS}_{\text {forecast }}-\mathrm{EPS}_{\text {actual }}}{\mathrm{EPS}_{\text {actual }}}-1$

Of particular interest to this study is Trombley's (2008) observation that low growth firms should have higher PEG ratios than high growth firms when fairly valued. ${ }^{2}$ From this, it can be deduced that the benchmark of PEG $=1.0$ (proposed by Lynch) can indeed be too simple, particularly for companies with one-year growth rates below 20\%, and that a share specific time-series model to estimate growth may be a more accurate means of setting benchmarks for the PEG ratio.

${ }^{2}$ Trombley (2008) graphically showed that this was in fact the case, although he did employ certain data trimming criteria.
The accuracy of analysts' forecasts and their ability to predict stock returns is an extensively researched subject, but with highly divided opinions. Dreman and Berry (1995) and Estrada (2004) both claim that analysts' earnings forecast errors are too large to be of reliable use to investors. Brown (1996) on the other hand argues against such findings, providing evidence that analysts' forecast EPS before quarterly announcements are within $3 \%$ of the actual EPS.

Conroy and Harris (1987) evaluated alternatives to using a single forecasting method through combinations of analysts' forecasts and forecasts derived from time series methods. They observe that analysts' forecast accuracy improves as the number of contributing forecasts increases. This was most apparent in the shortest forecast horizon, where they observed a $57 \%$ improvement in forecast accuracy when comparing a single analyst's forecast to the consensus forecasts of 16 analysts. Conroy and Harris (1987) also confirmed that the forecast accuracy decreased as the dispersion between analyst's forecasts increased. They also state that (1987: 737) "analysts' forecasting ability appears to be largely confined to forecasting horizons of less than one year and declines steadily as the forecast horizon increases". Similar findings were noted by Crichfield, Dyckman and Lakonishok (1978), O’Brien (1988), Brown (1996) and Prayag and Van Rensburg (2004). Furthermore, Conroy and Harris (1987), Lobo and Nair (1990) and Lobo (1992) all observed that combined forecasts (calculated as a simple average of analysts' forecasts and a time series forecast) significantly increase accuracy for any forecast horizon. Lobo (1992) identifies the fact that a combination of time-series and analysts' forecasts are particularly useful where there is a high level of forecast dispersion, as well as a low number of analyst contributions to the consensus forecast. Elgers and Lo (1994) and Mozes (2003) provide evidence that historical earnings can be used to adjust analysts' forecasts in such a way that it improves the accuracy of earnings forecasts.

Following from the constructs identified in the literature review, these hypotheses were tested:

\section{Hypothesis 1: PEG trading rule criteria}

The null hypothesis states that a PEG based trading rule will not outperform market returns.

$\begin{array}{ll}\mathrm{H} 1_{0}: & \mathrm{PEG} \mu_{\mathrm{AR}}=0 \\ \mathrm{H} 1_{\mathrm{A}}: & \mathrm{PEG} \mu_{\mathrm{AR}}>0\end{array}$

Three sub-hypotheses were also tested in terms of their ability to improve the PEG based trading rule. These related to the number of analysts contributing to the consensus forecast, the dispersion between their forecasts and the forecast horizon.

\section{Hypothesis 2: A PEG $_{\mathrm{T}}$ outperforms a $\mathrm{PEG}_{\mathrm{L}}$ trading rule strategy}

The null hypothesis states that a $\mathrm{PEG}_{\mathrm{T}}$ trading rule strategy based upon Trombley's (2008) valuation criteria will not outperform a $\mathrm{PEG}_{\mathrm{L}}$ trading rule strategy using Lynch's (1989) full value criteria around 1,0. 
$\mathrm{H} 2_{0}: \quad \mathrm{PEG}_{\mathrm{T}} \mu_{\mathrm{AR}}-\mathrm{PEG}_{\mathrm{L}} \mu_{\mathrm{AR}}=0$

$\mathrm{H} 2_{\mathrm{A}}: \quad \mathrm{PEG}_{\mathrm{T}} \mu_{\mathrm{AR}}-\mathrm{PEG}_{\mathrm{L}} \mu_{\mathrm{AR}}>0$

Hypothesis 3: Optimal PEG trading rule strategy

The null hypothesis states that an optimised PEG trading rule strategy will not outperform a normal PEG trading rule strategy.

$\mathrm{H}_{0}: \quad \mathrm{PEG}_{\mathrm{OPT}} \mu_{\mathrm{AR}}-\mathrm{PEG}_{\mathrm{NORM}} \mu_{\mathrm{AR}}=0$

$\mathrm{H}_{3}: \quad \mathrm{PEG}_{\mathrm{OPT}} \mu_{\mathrm{AR}}-\mathrm{PEG}_{\mathrm{NORM}} \mu_{\mathrm{AR}}>0$

\section{Research methodology}

The target population of this study was Johannesburg Stock Exchange (JSE) listed entities between October 2005 and June 2010, for which appropriate analyst's earnings forecasts were available. The period 2005 to 2010 was deemed appropriate being both recent, and volatile. Shares traded on the JSE experienced a strong bull period (to May 2008) followed by a market collapse (May 2008 - March 2009), before resuming a positive trend to October 2010. The final sample for the study comprised 101 listed shares from the industrial, resource and financial sectors, of which the total market capitalisation amounted to approximately $93 \%$ of the entire JSE.

Historical closing price data was obtained from the McGregor BFA database for the period of Jan 2000 to June 2010. Historical reported (actual) EPS data over the same period and historical analyst's consensus forecasts of EPS from October 2005 to June 2010 were sourced from INET Bridge. The following variables were compiled:

- The announcement date

- Median EPS consensus forecast

- $\quad$ Entity year-end date

- Number of analysts contributing to the consensus forecast $(\mathrm{N})$

- $\quad$ Standard deviation of forecasts by analysts (SD)

The following variables were calculated for each of the analysts' consensus forecasts:

- Forecast Dispersion - the standard deviation as a percentage of the median consensus forecasts amount $(\mathrm{SD} \%)$ :

$\mathrm{SD}=\frac{\mathrm{Stan} \text { dard Deviation }(\mathrm{SD})}{\text { Median EPS forecast }}$
- Forecast horizon - calculated in months, being the difference between announcement date and year-end date $(\mathrm{FH})$ :

$\mathrm{FH}=\left[\text { Date }_{\text {year end }}-\text { Date }_{\text {forecast }}\right]_{\text {months }}$

The following steps were used to develop the research instrument:

Step 1: The closing price on the first trading day of every calendar month from October 2005 to June 2010 (57 monthly intervals) for the sample of 101 equities was established, thereby creating a 101 x 57 matrix.

Step 2: The reported EPS (actual) was then cross tabulated in a separate matrix for all equities over the 57 month period. This remained constant for the 12 months immediately following each year-end announcement.

Step 3: The trailing $P E$ ratio was then calculated in a resultant 101 x 57 matrix by dividing the closing price obtained in step 1 by the reported EPS from step 2 .

Step 4: The forecast EPS was the current consensus analyst's forecast, and unlike the actual reported EPS, the forecast EPS changed whenever a revised forecast was made by analysts.

Step 5: The Growth\% was then calculated in a resultant 101 x 57 matrix by using the actual reported $\mathrm{EPS}_{\text {actual }}$ and the median analyst's forecast EPS $_{\text {forecast }}$ as shown in equation 1 .

Step 6: The PEG ratio constituted the final $101 \times 57$ matrix, constructed by dividing the PE ratio from step 3 with the Growth\% from step 5.

Step 7: Separate matrices were created for each of the three factors which were to be tested in the sub-hypotheses: the number of analysts contributing to the forecast $(\mathrm{N})$, the forecast dispersion (standard deviation) of the forecasts as a percentage of the median forecast EPS (SD\%), and the forecast horizon $(\mathrm{FH})$.

The data were split into two approximately equal subsets, as shown by the ranges described in Table 1 below.

Table 1: Selected factor sub-set ranges

\begin{tabular}{l|c|c}
\hline Factor & Sub-Set 1 & Sub-Set 2 \\
\hline No. of Analysts' Contributions (N) & $0<\mathrm{N} \leq 6$ & $7 \leq \mathrm{N} \leq 14$ \\
\hline Forecast Dispersion (SD $\%)$ & $0 \% \leq \mathrm{SD} \% \leq 10 \%$ & $10 \%<\mathrm{SD} \% \leq 130+\%$ \\
\hline Forecast Horizon (FH) & $0<\mathrm{FH} \leq 6.1$ & $6,1<\mathrm{FH} \leq 12$ \\
\hline
\end{tabular}


Step 8: Matrices of dummy variables (1 or 0$)$ were constructed to represent the filtering criteria described above, for each share.

Step 9: By multiplying the dummy variables with the calculated PEG ratio, observations could then be included or eliminated (i.e. filtered) from evaluation in accordance with the defined factors.

According to Lynch (1989), the following trading rules should be used when evaluating the PEG ratio (see Table 2):

Trombley's (2008) observation that the 'appropriate' PEG ratio varies across differing growth rates was examined using the sample of 101 equities over the period of January 2000 to June 2010. An adjustment was made to Trombley's (2008) methodology in that the 'historical PE' ratio was used to calculate the PEG ratio and not the 'leading PE' ratio. After applying the same data trimming techniques used by Trombley (2008), a similar relationship between PEG and G\% was confirmed (see Figure 1).

Trombley's (2008) observed relationship between the PEG ratio and the growth rate provides the basis for an alternative trading rule, as shown below:

$$
\mathrm{PEG}=0,167 \times \mathrm{G} \%
$$

Thus, given a forecast Growth\%, one is able to calculate a PEG ratio that would indicate fair value of the share. However, Estrada (2004), Trombley, (2008) and Schnabel (2009) all noted that companies' PEG ratios are individually affected by additional factors, including risk (market beta), debt service levels and the cost of capital. On the basis of these observations, each of the 101 shares in the sample was individually fitted with a unique power regression model, using out-of-sample data 5-years preceding the 57 monthly share valuation dates. This model was revised and updated with actual market and growth data on a rolling basis, and is denoted by $\mathrm{PEG}_{\mathrm{T} \text { CALC. }}$ The following trading rule was then established (see Table 3):

To test the trading rules, portfolios were created by observing the relevant PEG trading signal and buying, holding or selling shares depending on the trading rule criteria. Resultant gains and losses were calculated using accumulated 'average monthly returns' from participating shares on the first trading day of every month. By averaging monthly returns, an equal weighted portfolio was achieved, with monthly re-balancing.

Portfolio comparative performances were evaluated following Du Plessis and Ward (2009) and Anderson (2009):

A benchmark portfolio was established through buying all 101 participating equities with equally allocated capital and then holding from October 2005 to June 2010, with no readjustment or rebalancing.

'Abnormal Returns' (AR) were calculated between the portfolio returns and the benchmark. Where applicable, abnormal returns were also calculated between PEG portfolios, in order to test for the significance in the difference in returns. Paired t-Tests were used to test all hypotheses. The test was applied to pairs of returns for the different sub-set portfolios for each of the PEG trading rule criteria (i.e. $\mathrm{PEG}_{\mathrm{T}}$ and $\mathrm{PEG}_{\mathrm{L}}$ ). Similarly, the test was applied to pairs of returns for the different subset-portfolios when testing for difference of means between the two trading rules criteria. Non-parametric test statistics were applied to portfolio returns that did not have either a normal distribution or equal variance and were thus not eligible for the t-Test. These tests included: the Wilcoxon Signed-Rank Test, Mann-Whitney U or Wilcoxon Rank-Sum Test, and Aspin-Welch Unequal-Variance Test.

A number of limitations are noted. Transaction costs on trading were calculated for the optimal trading rule on the basis of a total fee per trade (buy and sell) of $0.5 \%$. All trading funds were assumed to be in the market (i.e., a cash portfolio was not maintained). Liquidity constraints were ignored, with all trades assumed to occur at the closing prices on the first day of the month, irrespective of the fact that trading signals may have occurred within the previous month.

\section{Results}

The analyst forecast data used in this research comprised of a total of 6,530 consensus forecasts. The average number of forecasts per entity over this period equated to a mean of 155 , with a standard deviation of 40 . The highest number of forecasts per equity was 197 and the lowest number of forecasts was 60 per equity.

Table 2: PEG Trading rule criteria for $\mathrm{PEG}_{\mathrm{L}}(\mathrm{Lynch}, 1989)$

\begin{tabular}{|c|c|c|c|}
\hline Position & $\mathbf{P E G}_{\mathbf{L}}$ & Signal & Sym. \\
\hline Not held & PEG $<0.1$ or $\mathrm{PEG}>0.5$ & HOLD (Out) & $\mathrm{H}-$ \\
\hline Not held & $0.1 \leq \mathrm{PEG} \leq 0.5$ & BUY & $\mathrm{B}$ \\
\hline Held & Any $\mathrm{PEG}<2.0$ & HOLD (In) & $\mathrm{H}+$ \\
\hline Held & $\mathrm{PEG} \geq 2.0$ & SELL & $\mathrm{S}$ \\
\hline
\end{tabular}




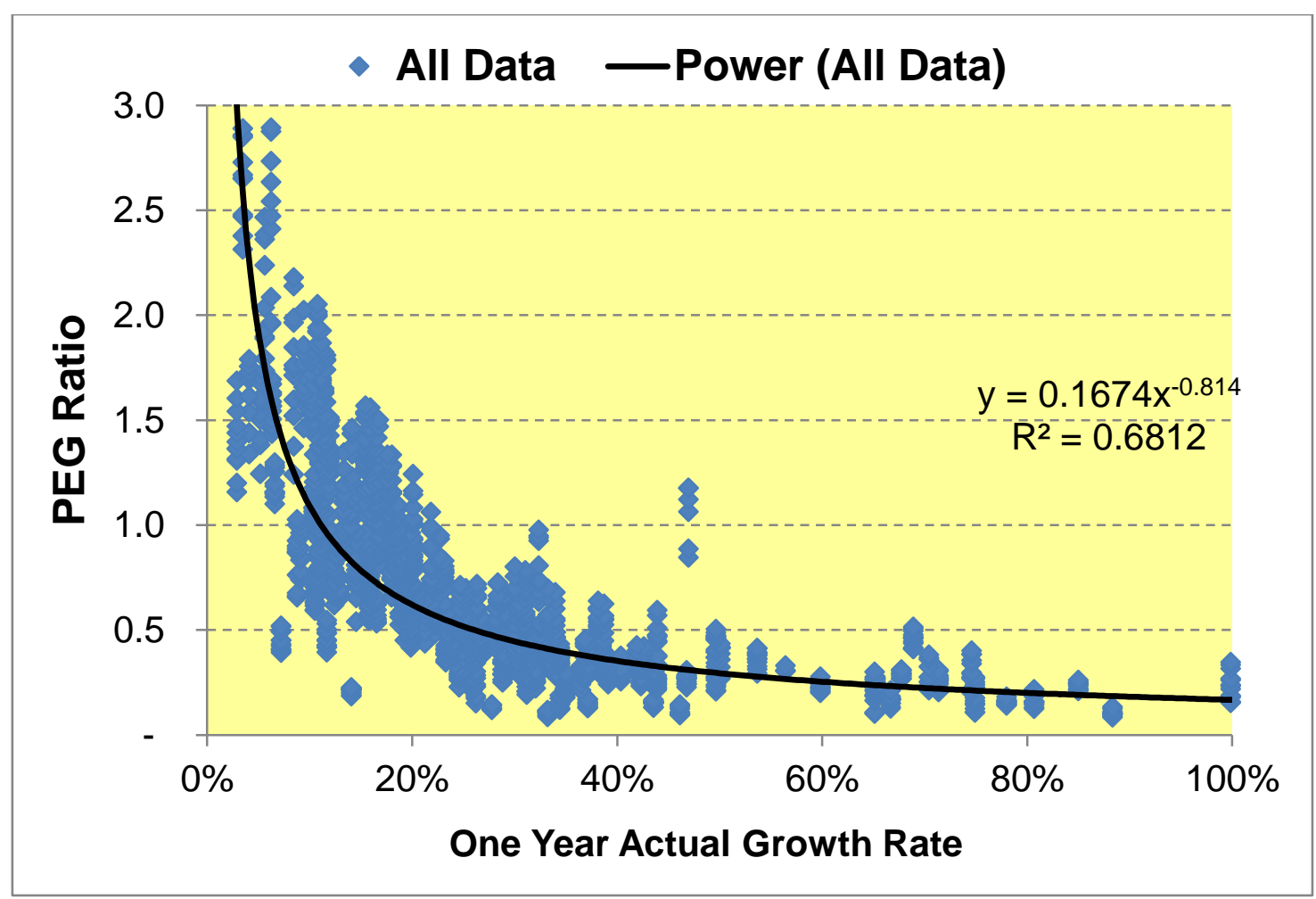

Figure 1: Confirming Trombley's (2008) observation of PEG vs. G\%

Table3: PEG trading rule criteria for PEG $_{\mathrm{T}}$ (Trombley, 2008)

\begin{tabular}{c|c|c|c}
\hline Position & PEG $_{\mathbf{T}}$ & Signal & Sym. \\
\hline Not held & PEG $<0,1$ or PEG $>200 \% \times$ PEG $_{\mathrm{T} \text { CALC }}$ & HOLD (Out) & H- \\
\hline Not held & $0,1 \leq$ PEG $\leq\left(50 \% \times\right.$ PEG $\left._{\mathrm{T} \text { CALC }}\right)$ & BUY & B \\
\hline Held & Any PEG $<\left(200 \% \times\right.$ PEG $\left._{\mathrm{T} \text { CALC }}\right)$ & HOLD (In) & H+ \\
\hline Held & PEG $\geq\left(200 \% \times\right.$ PEG $\left._{\mathrm{T} \text { CALC }}\right)$ & SELL & S \\
\hline
\end{tabular}

\section{Hypothesis 1: Normal PEG trading rule criteria}

The objective was to assess the PEG ratio in its simplest form as a trading indicator for stock selection purposes (as per Lynch, 1989; Easton, 2004; Estrada, 2004; Trombley, 2008; Schatzberg \& Vora, 2009; Schnabel, 2009):

Following Lynch's (1989) $\mathrm{PEG}_{\mathrm{L}}$ benchmarking criteria (i.e. undervalue $\leq 0.5$, fair-valued $=1.0$ and overvalue $\geq 2.0$ ) the study found portfolio returns to be almost exactly the same as the benchmark returns over the test period, delivering $186 \%$ and $189 \%$ respectively. Furthermore, there was almost no deviation from the benchmark by the $P_{E G}$ portfolio as indicated by the relative return. Statistical tests confirmed that the null hypothesis could not be rejected.

Trombley's (2008) PEG $_{\mathrm{T}}$ portfolio returned a total of $215 \%$ over the test period compared to the benchmark return of $189 \%$, translating to a statistically significant $(\mathrm{p}=0.0415)$ annualised return of $3.1 \%$ over the market. However, as seen in Figure 2, the graph of the price relative shows that all of the out-performance occurred in the first half of the time-series. The null hypothesis was rejected, implying that a simple PEG $_{\mathrm{T}}$ trading rule strategy can outperform normal market returns.
Hypothesis 2: A PEG $_{\mathrm{T}}$ outperforms a $\mathrm{PEG}_{\mathrm{L}}$ trading rule strategy

Conroy and Harris (1987) observed that analysts forecast errors decreased as the number of analysts contributions to the consensus forecast increased. Therefore it was anticipated that the higher analyst sub-set $(7<\mathrm{N} \leq 14)$ would provide more accurate earnings growth forecasts, and hence better PEG ratios, than the lower analyst sub-set $(0<\mathrm{N}<6)$. Although not statistically significant, this was not the finding in this study, as both the $\mathrm{PEG}_{\mathrm{L}}$ and $\mathrm{PEG}_{\mathrm{T}}$ trading rule showed that the portfolio with fewer analysts delivered higher returns than the portfolio with more analysts.

Conroy and Harris (1987) and Lobo (1992) both suggested that a lower dispersion in analyst's forecasts would result in more accurate forecasts. For both the $\mathrm{PEG}_{\mathrm{L}}$ and $\mathrm{PEG}_{\mathrm{T}}$ trading rule, this study found that the portfolio with the higher dispersion in forecasts yielded greater (although not statistically different) returns than the lower dispersion in forecasts portfolio.

Crichfield and Lakonishok (1978), Conway and Harris (1987), O’Brien (1988), Brown (1996), Prayag and Van Rensburg (2004) all found that analysts' forecasts become more accurate as the announcement date approaches (i.e. as the forecast horizon decreases). The results of this study 
showed that, for both the $\mathrm{PEG}_{\mathrm{L}}$ and $\mathrm{PEG}_{\mathrm{T}}$ trading rule, portfolios with longer forecast horizons (between 6 and 12 months) delivered the highest returns when using the trading rule. Once again, the findings were not statistically significant (see Table 4).

Although it would be reasonable to expect that an improvement in the accuracy of analysts' consensus forecasts would lead to a more useable PEG ratio as a stock selection tool, this was not the finding.

Hypothesis 3: Optimal PEG trading rule strategy Although statistical significance was not found in the above results, the best performing portfolio results for both the $\mathrm{PEG}_{\mathrm{L}}$ and $\mathrm{PEG}_{\mathrm{T}}$ trading strategies were obtained for the following sub-sets:
- Number of analyst contributions (N): $0<\mathrm{N} \leq 6$

- Forecast dispersion (SD\%): $10 \%<\mathrm{SD} \% \leq 130+\%$

- $\quad$ Forecast horizon (FH): $6.1 \leq \mathrm{FH} \leq 12$

By including a combination of the above three factors into the trading rule for the $\mathrm{PEG}_{\mathrm{L}}$ and $\mathrm{PEG}_{\mathrm{T}}$ portfolios, a dramatic improvement in portfolio returns of $234 \%$ (CAGR: 19,7\%) and 329\% (CAGR: 28,5\%) respectively was observed, although transaction costs would have reduced these returns by approximately $1 \%$ over the period (see Table 5). These results were far higher than the benchmark return of $189 \%$ (CAGR: 14,4\%), resulting in statistically significant p-values of 0,0269 and 0,0146 . The graph of the price relative however, showed that the strategies only worked in the first half of the time-series (see Figure 3).

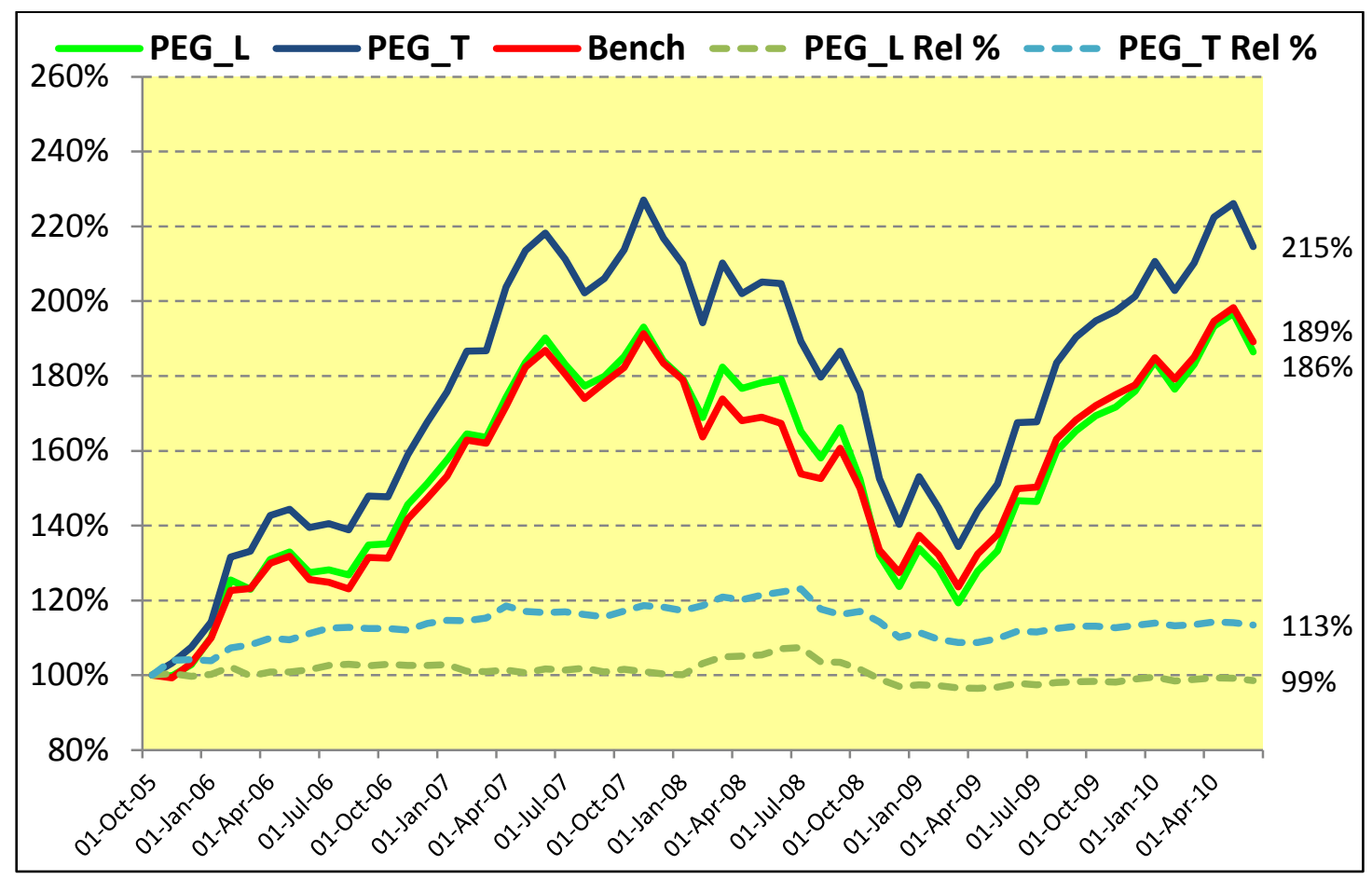

Figure2: Comparison of 'normal' PEG trading rule portfolios 
Table 4: Hypothesis test statistics

\begin{tabular}{|c|c|c|c|c|c|c|}
\hline Portfolio & PEG $_{L}$ & PEG $_{T}$ & PEG $_{\mathrm{L}}$ & PEG $_{T}$ & PEG $_{\mathrm{L}}$ & PEG $_{T}$ \\
\hline Null Hypothesis & $\mu_{\mathrm{AR} \mathrm{N} 2}-\mu_{\mathrm{AR} \mathrm{N} 1}=0$ & $\mu_{\mathrm{ARN} 2}-\mu_{\mathrm{ARN} 1}=0$ & $\begin{array}{l}\mu_{\mathrm{AR} \mathrm{SD} 1 \%}-\mu_{\mathrm{AR} \mathrm{SD}} \% 2= \\
0\end{array}$ & $\begin{array}{l}\mu_{\mathrm{AR} \mathrm{SD} 1 \%}-\mu_{\mathrm{AR} \mathrm{SD}} \% 2= \\
0\end{array}$ & $\mu_{\mathrm{AR} \mathrm{FH} 1}-\mu_{\mathrm{AR} \mathrm{FH} 2}=0$ & $\mu_{\mathrm{AR} \mathrm{FH} 1}-\mu_{\mathrm{AR} \mathrm{FH} 2}=0$ \\
\hline $\begin{array}{l}\text { Alternative } \\
\text { Hypothesis }\end{array}$ & $\mu_{\mathrm{ARN} 2}-\mu_{\mathrm{ARN} 1}>0$ & $\mu_{\mathrm{AR} \mathrm{N} 2}-\mu_{\mathrm{ARN} 1}>0$ & $\begin{array}{l}\mu_{\mathrm{AR} \mathrm{SD} 1 \%}-\mu_{\mathrm{AR} \mathrm{SD} 2} \% \\
0\end{array}$ & $\begin{array}{l}\mu_{\mathrm{AR} \mathrm{SD} 1} \%-\mu_{\mathrm{AR} \mathrm{SD} 2} \% \\
0\end{array}$ & $\mu_{\mathrm{AR} \mathrm{FH} 1}-\mu_{\mathrm{ARFH} 2}>0$ & $\mu_{\mathrm{ARFH} 1}-\mu_{\mathrm{AR} \mathrm{FH} 2}>0$ \\
\hline $\begin{array}{l}\text { Significance } \\
\text { Level }\end{array}$ & $5 \%$ & $5 \%$ & $5 \%$ & $5 \%$ & $5 \%$ & $5 \%$ \\
\hline $\begin{array}{l}\text { Mean } \\
\text { Difference }\end{array}$ & $0,31 \%$ & $-0,15 \%$ & $-0,33 \%$ & $-0,32 \%$ & $-0,10 \%$ & $-0,19 \%$ \\
\hline $\begin{array}{l}\text { Standard } \\
\text { Deviation }\end{array}$ & $2,04 \%$ & $2,37 \%$ & $2,60 \%$ & $2,78 \%$ & $1,98 \%$ & $1,61 \%$ \\
\hline Standard Error & $0,39 \%$ & $0,45 \%$ & $0,35 \%$ & $0,37 \%$ & $0,27 \%$ & $0,30 \%$ \\
\hline $\begin{array}{l}\text { Normal } \\
\text { distribution? }\end{array}$ & Normal & Reject Normality & Reject Normality & Normal & Reject Normality & Normal \\
\hline Variance? & Equal & Equal & Reject Equal Var. & Reject Equal Var. & Reject Equal Var. & Equal \\
\hline Type of Test & $\begin{array}{l}\text { Equal Variance T- } \\
\text { Test }\end{array}$ & $\begin{array}{l}\text { Mann-Whitney U } \\
\text { or Wilcoxon Rank- } \\
\text { Sum Test }\end{array}$ & $\begin{array}{l}\text { Aspin-Welch } \\
\text { Unequal-Variance }\end{array}$ & $\begin{array}{l}\text { Aspin-Welch } \\
\text { Unequal-Variance }\end{array}$ & $\begin{array}{l}\text { Aspin-Welch } \\
\text { Unequal-Variance }\end{array}$ & $\begin{array}{l}\text { Equal Variance T- } \\
\text { Test }\end{array}$ \\
\hline $\begin{array}{l}\text { Degrees of } \\
\text { Freedom }\end{array}$ & 110 & 110 & 84 & 87 & 101 & 110 \\
\hline $\begin{array}{l}\text { t-Value / z- } \\
\text { Value }\end{array}$ & 0,8122 & 0,1717 & $-0,9415$ & $-0,8685$ & $-0,3853$ & $-0,6235$ \\
\hline $\begin{array}{l}\text { p-Value (1 } \\
\text { tailed) }\end{array}$ & 0,7908 & 0,5682 & 0,8254 & 0,8063 & 0,6496 & 0,7329 \\
\hline $\begin{array}{l}\text { Reject Null } \\
\text { Hypothesis? }\end{array}$ & No & No & No & No & No & No \\
\hline
\end{tabular}

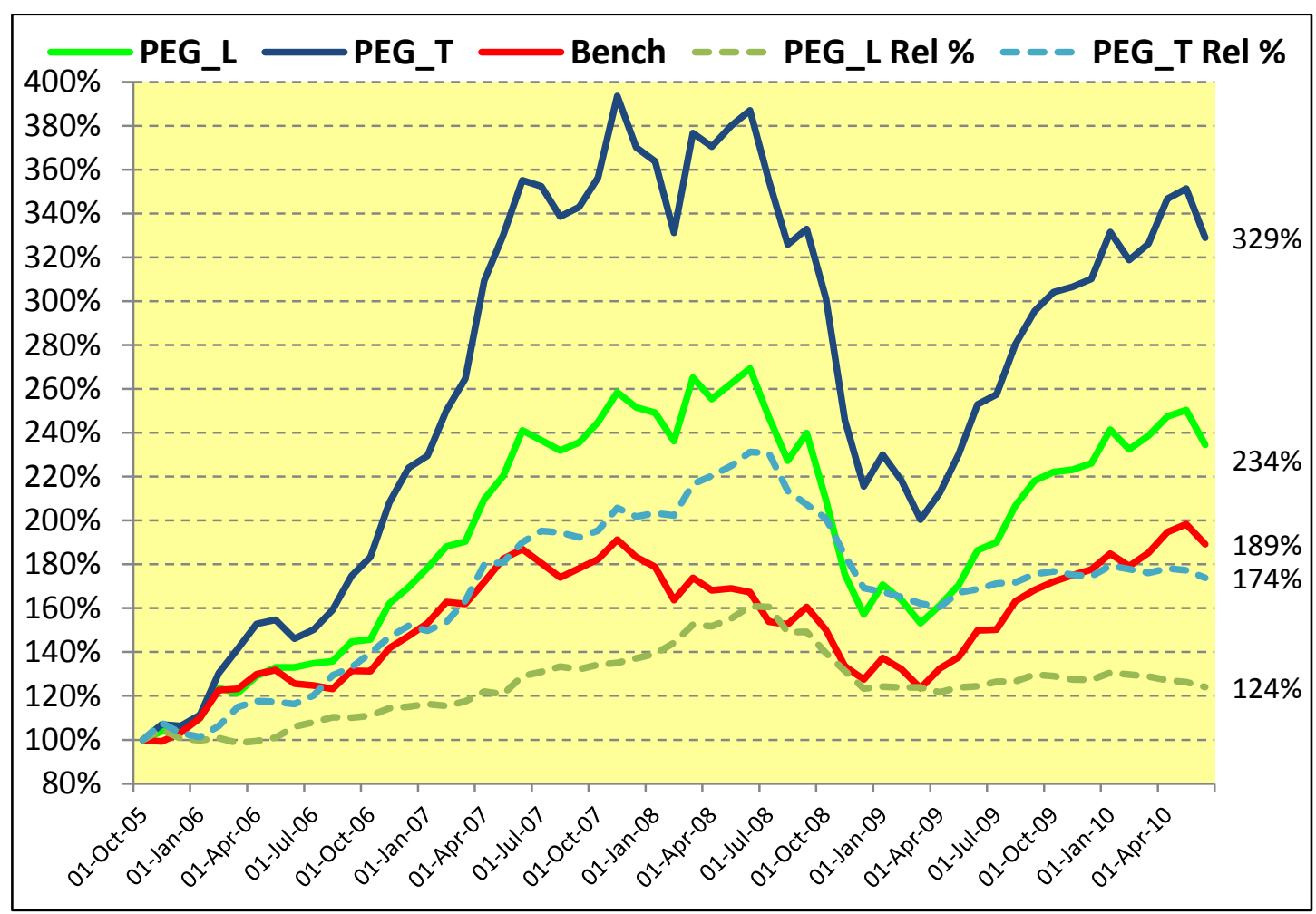

Figure 3: Comparison of optimal PEG trading rule portfolios 
Table 5: Portfolio performances of optimal PEG trading rules

\begin{tabular}{|c|c|c|c|}
\hline Portfolio & $\mathbf{P E G}_{\mathrm{L}}$ & PEG $_{\mathrm{T}}$ & Bench \\
\hline Start $(\%)$ & $100 \%$ & $100 \%$ & $100 \%$ \\
\hline End $(\%)$ & $234 \%$ & $329 \%$ & $189 \%$ \\
\hline Ave. No. of Shares Held & 24 & 13 & 101 \\
\hline Max. Portfolio value allocated to any share & $16,70 \%$ & $33,30 \%$ & $1,00 \%$ \\
\hline Compound Annual Growth Rate CAGR(\%) & $19,70 \%$ & $28,50 \%$ & $14,40 \%$ \\
\hline Annualised Standard Deviation SD(\%) & $21,20 \%$ & $25,20 \%$ & $17,20 \%$ \\
\hline Risk Free Rate & $8,5 \%$ & $8,5 \%$ & $8,5 \%$ \\
\hline Annualised Sharpe Ratio & 0,537 & 0,801 & 0,353 \\
\hline $\begin{array}{l}\text { Annual Abnormal Return with respect to } \\
\text { Benchmark }\end{array}$ & $5,40 \%$ & $13,70 \%$ & - \\
\hline Total transaction costs & $0,94 \%$ & $0,92 \%$ & - \\
\hline Null Hypothesis & $\mathrm{PEG}_{\mathrm{L} \text { OPT }} \mu_{\mathrm{AR}}=0$ & $\mathrm{PEG}_{\mathrm{T} \mathrm{OPT}} \mu_{\mathrm{AR}}=0$ & \\
\hline Alternative Hypothesis & $\mathrm{PEG}_{\mathrm{L} \text { OPT }} \mu_{\mathrm{AR}}>0$ & $\mathrm{PEG}_{\mathrm{T} \text { OPT }} \mu_{\mathrm{AR}}>0$ & \\
\hline Significance Level & $5 \%$ & $5 \%$ & \\
\hline Mean Difference & $0,46 \%$ & $1,14 \%$ & \\
\hline Standard Deviation & $2,66 \%$ & $3,82 \%$ & \\
\hline Standard Error & $0,36 \%$ & $0,51 \%$ & \\
\hline Normal distribution? & Reject Normality & Normal & \\
\hline Type of Test & Wilcoxon Signed-Rank Test & T-Test & \\
\hline Number of Ties & 4 & - & \\
\hline z-Value / t-Value & 1,9287 & 2,2407 & \\
\hline p-Value ( 1 tailed) & 0,0269 & 0,0146 & \\
\hline Reject Null Hypothesis? & Yes & Yes & \\
\hline
\end{tabular}

\section{Conclusions}

This study found evidence to show that Lynch's (1989) $\mathrm{PEG}_{\mathrm{L}}$ valuation criteria is too simplistic and that the additional factors identified by Estrada (2004), Trombley (2008) and Schnabel (2009) should be included to improve the usefulness of the PEG ratio. A $\mathrm{PEG}_{\mathrm{T}}$ based trading model significantly outperformed both the $\mathrm{PEG}_{\mathrm{L}}$ and the benchmark portfolios, with an annual abnormal return of $3,1 \%$.

The analysis also found an association between portfolio performance and variables affecting the accuracy of analyst's earnings forecasts, such as: the number of analysts contributing to the consensus forecast, the dispersion of the analysts' forecasts and the forecast horizon. Although statistically insignificant, the direction of these associations implied that the PEG metric improved as the forecasts became less accurate.
As this outcome was unexpected, additional literature identified that a major reason for inaccurate forecasts is analyst optimism. This has been well documented by Das, Levine and Sivaramakrishnan (1998), Duru and Reeb (2002), Francis and Philbrick (1993), Elgers and Lo (1994), Durgar and Nathan (1995), Hunton and McEwen (1997), O'Brien (1998), Dechow, Hutton and Sloan (2000), McNichols and O'Brien (1997), Hong and Kubik (2003), Scherbina (2004) and Clement and Tse (2005). Optimistic forecasts would lead to estimates of growth which are too high. When applied to the PEG ratio, these optimistic growth estimates would reduce the PEG ratio, changing the timing of the Buy and Sell trading signals, which actually improved the results.

The inclusion of filters to screen observations on forecast accuracy (i.e. those with fewer analysts contributing, with high dispersion and with longer forecasting horizons) 
resulted in an 'optimised' PEG trading rule that significantly outperformed normal market returns for both $\mathrm{PEG}_{\mathrm{L}}$ and $\mathrm{PEG}_{\mathrm{T}}$ portfolios, with annual abnormal returns of $5.4 \%$ (CAGR: $19.7 \%$ ) and $13.7 \%$ (CAGR: $28.5 \%$ ) respectively.

Further examination revealed that this methodology had identified 'small firm' stocks (by market capitalisation) with high (relative) PE ratios which can be classified as 'growth stocks'. These are likely to perform well during the expansion and recovery phase of the economic cycle, as reflected in our results.

In conclusion, we find that Trombley's (2008) PEG model is a useful predictor of under-/over-valued shares. Furthermore, PEG based trading strategies have the potential to enable investors to outperform market returns on the JSE.

\section{References}

Anderson, G. 2009. Unit trust fund holdings and stock returns. Johannesburg, Illovo: Gordon Institute of Business Science.

Bradshaw, M.T. 2006. 'How do analysts forecast earnings and what do they do with these forecasts?' In: Proceedings of the Centre for Accounting Research and Education Conference. April, Notre Dame. Indiana: Cambridge Business Publishers.

Brown, L.D. 1996. 'Analyst forecasting errors and their implications for security analysis: An alternative perspective', Financial Analysts Journal, 52: 40-46.

Clement, M.B. \& Tse, S.Y. 2005. 'Financial analysts' characteristics and herding behaviour in forecasting', The Journal of Finance, 60(1): 307-341.

Clemente, H.A. 1990. 'What Wall Street sees when it looks at your PE ratio', Financial Executive, 1 May: 40-44.

Conroy, R. \& Harris, R. 1987. 'Consensus forecasts of corporate earnings: Analysts' forecasts and time series methods', Management Science, 33(6): 725-738.

Crichfield, T.T.D. \& Lakonishok, J. 1978. 'An evaluation of security analysts' forecasts', The Accounting Review, 3: 651-668.

Das, S., Levine, C.B. \& Sivaramakrishnan, K. 1998. 'Earnings predictability and bias in analyst's earnings forecasts', The Accounting Review, 73: 277-294.

Dechow, P.M., Hutton, A.P. \& Sloan, R.G. 2000. 'The relationship between analyst's forecasts of long-term earnings growth and stock price performance following equity offerings', Contemporary Accounting Research, 17(1): 1-32.

Dreman, D.N. \& Berry, M.A. 1995. 'Analyst forecasting errors and their implications for security analysis', Financial Analysts Journal, 51(3): 30-41.
Du Plessis, A. \& Ward, M. 2009. 'A note on applying the Markowitz Portfolio Selection Model as a passive investment strategy on the JSE', Investment Analysts's Journal, 69: 39-46.

Dudney, D., Jirasakildech, B. \& Zorn, T. 2008. 'Return predictability and the $\mathrm{P} / \mathrm{E}$ ratio: Reading the entrails', The Journal of Investing, 17(3): 75-82.

Durgar, A. \& Nathan, S. 1995. 'The effect of investment banking relationships on financial analysts' earnings forecasts and investment recommendations', Contemporary Accounting Research, 12: 131-160.

Duru, A. \& Reeb, D. M. 2002. 'International diversification and analysts' forecast accuracy bias', The Accounting Review, 77(2): 415-433.

Easton, P.D. 2004. 'PE ratios, PEG ratios, and estimating the implied expected rate of return on equity capital', The Accounting Review, 79(1): 73-95.

Elgers, P.T. \& Lo, M.H. 'Reductions in analysts' annual earnings forecast errors using information in prior earnings and security returns', Journal of Accounting Research, 32(2): 290-303.

Estrada, J. 2004. 'Adjusting $\mathrm{P} / \mathrm{E}$ ratios by growth and risk: A note', Finance Letters, 2(5): 4-10.

Fama, E. \& French, K. 1992. 'The cross section of expected stock returns', Journal of Finance, 47: 427-465.

Francis, J. \& Philbrick, D. 1993. 'Analysts' decisions as products of multi-task environment', Journal of Accounting Research, 31: 216-230.

Hong, H. \& Kubik, J.D. 2003. 'Analysing the analysts: Career concerns and bias earnings forecasts,' Journal of Finance 58(1): 313-351.

Hunton J.E. \& McEwan, R.A. 1997. 'An assessment of the relation between analysts' earnings forecast accuracy, motivational incentives and cognitive information search strategy',. The Accounting Review, 65: 1124-1131.

Investopedia. 2010a. 'Home - dictionary: Analyst'. [online] URL: $\quad$ http://www.investopedia.com/terms/a/analyst.asp. Accessed 11 April 2010.

Investopedia. 2010b. 'Dictionary: Price-earnings ratio - P/E ratio'. [online] URL: http://www.investopedia.com/terms/p/price-arningsratio.asp. Accessed 15 April 2010.

Investopedia. 2010c. 'The greatest investors: James D. Slater'. [online] URL:

http://www.investopedia.com/university/greatest/jamesslater .asp. Accessed 24 April 2010. 
Investopedia. 2010d. 'Efficient market hypothesis - EMH'. [online] URL:

http://www.investopedia.com/terms/e/efficientmarkethypoth esis.asp. Accessed 24 October 2010.

Investopedia. 2002. 'The P/E ratio tutorial'. [online] URL: http://www.investopedia.com/university/peratio/default.asp. Accessed 24 April 2002.

Lobo, G. 1992. 'Analysis and comparison of financial analysts', time series and combined forecasts of annual earnings', Journal of Business Research, 24: 269-280.

Lobo, G. \& Nair, R. 1990. 'Combining judgemental and statistical forecasts: An application to earnings forecasts', Descision Sciences, 21: 446-460.

Lynch, P. 1989. One up on Wall Street. New York: Penguin Books.

McNichols, M. \& O’Brien, P. C. 1997. 'Self selection and analyst coverage', Journal of Accounting Research, 35: 167199.

Mozes, H.A. 2003. 'Accuracy, usefulness and the evaluation of analysts' forecasts', International Journal of Forecasting, 19: 417-434.

O'Brien, P.C. 1988. 'Analysts' forecast as earnings expectations', Journal of Accounting and Economics, 10: 53-83.

Prayag, C. \& Van Rensburg, P. 2004. 'Accuracy of brokers' consensus earnings forecasts: The South African case', Investment Analysts Journal, 59: 21-30.

Schatzberg, J.D. \& Vora, G. 2009. 'PEG investing strategy: A revisit', Quarterly Journal of Finance and Accounting, 48: 5-22.

Scherbina, A. 2004. 'Analyst disagreement, forecast bias and stock returns'. [online] URL: [online] URL:

http://hbswk.hbs.edu/item/5418.html. Retrieved from Hardvard Business School - Working Knowledge.

Schnabel, J.A. 2009. 'Benchmarking the PEG ratio', The Journal of Wealth Management, 12(3): 89-94.

Trombley, M.A. 2008. 'Understanding the PEG ratio', The Journal of Investing, 17(1): 22-25. 